Centre interuniversitaire de recherche

en économie quantitative

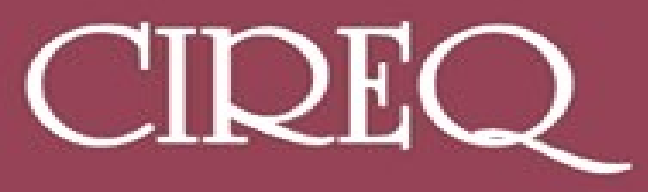

Cahier 19-2006

TAX DIFFERENTIALS AND THE SEGMENTATION OF NETWORKS OF COOPERATION IN OLIGOPOLY

Hassan BENCHEKROUN and Denis CLAUDE 


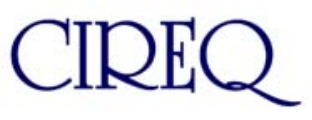

Le Centre interuniversitaire de recherche en économie quantitative (CIREQ) regroupe des chercheurs dans les domaines de l'économétrie, la théorie de la décision, la macroéconomie et marchés financiers, la microéconomie appliquée et économie expérimentale et l'économie de l'environnement et des ressources naturelles. Ils proviennent principalement des universités de Montréal, McGill et Concordia. Le CIREQ offre un milieu dynamique de recherche en économie quantitative grâce au grand nombre d'activités qu'il organise (séminaires, ateliers, colloques) et de collaborateurs qu'il reçoit chaque année.

The Center for Interuniversity Research in Quantitative Economics (CIREQ) regroups researchers in the fields of econometrics, decision theory, macroeconomics and financial markets, applied microeconomics and experimental economics, and environmental and natural resources economics. They come mainly from the Université de Montréal, McGill University and Concordia University. CIREQ offers a dynamic environment of research in quantitative economics thanks to the large number of activities that it organizes (seminars, workshops, conferences) and to the visitors it receives every year.

Cahier 19-2006

\author{
TAX DIFFERENTIALS AND THE \\ SEGMENTATION OF NETWORKS OF \\ COOPERATION IN OLIGOPOLY
}

\author{
Hassan BENCHEKROUN and Denis CLAUDE
}

CIREQ, Université de Montréal C.P. 6128 , succursale Centre-ville Montréal (Québec) H3C 3J7 Canada téléphone : (514) 343-6557 télécopieur : (514) 343-5831 cireq@umontreal.ca http://www.cireq.umontreal.ca
Université th de Montréal 
Dépôt légal - Bibliothèque nationale du Canada, 2006, ISSN 0821-4441

Dépôt légal - Bibliothèque et Archives nationales du Québec, 2006

ISBN-13 : 978-2-89382-541-0; ISBN-10 : 2-89382-541-9 


\title{
Tax differentials and the segmentation of networks of cooperation in oligopoly*
}

\author{
Hassan Benchekroun \\ Department of Economics, CIREQ, McGill University \\ hassan.benchekroun@mcgill.ca
}

\author{
Denis Claude \\ HEC Montreal \& Gerad \\ dcecopub-web@yahoo.fr
}

October 28, 2006

\begin{abstract}
This paper study the effects of uncoordinated environmental tax policies on firms' incentives to form bilateral R\&D collaborations. It is shown that the complete network is pair-wise stable for small differences in the taxation of environmental emissions. Larger tax differentials may induce firms to broke all their international collaborations.
\end{abstract}

Keywords: Uncoodinated environmental actions, Taxation, Networks, R\&D

JEL classifications: Q55, L13, L20

\footnotetext{
${ }^{*}$ We are grateful to the participants of the 15th annual meeting of the Canadian Resource and Environmental Economics Study Group for helpful comments. Financial support of SSHRC and FQRSC is gratefully acknowledged. The usual disclaimer applies.
} 


\section{Introduction}

Government regulations provide powerful incentives for firms to invest in $R \& D$ to abate their pollution emissions ${ }^{1}$. In recent years, the way firms organize to develop "environment-friendly" innovations has known important mutations. First, there has been a sharp increase in the number of strategic research partnerships through which firms undertake R\&D to achieve emissions reduction. Second, empirical works (e.g., Hagedoorn (1996)) have highlighted that most of newly established $R \& D$ partnerships are non-equity based $R \& D$ agreements ${ }^{2}$. These partnerships are usually bilateral and define collectively a network of collaboration.

The purpose of this paper is to study how the difference in the tax on pollution emissions across countries affects the structure of stable networks of collaboration to abate pollution emissions. More specifically we consider two countries, firms in each country are charged a tax on their pollution emissions and the tax rate on pollution emissions may differ across countries. Following Goyal and Joshi (2003)'s seminal work, we consider a two stage game in which firms first sign bilateral R\&D agreements in order to achieve cost savings and then compete on the market of output. We consider a competition à la Cournot. In our model the R\&D agreements achieve cost savings through the abatement of pollution emissions (i.e., a reduction in the emission/output ratio) and the resulting decrease in the tax the firm pays per unit of output produced.

We show that, when the difference between each country's tax rate on pollution emissions is small enough, the complete network is pair-wise stable: international R\&D collaboration occurs. This is in line with Goyal and Joshi (2003) which shows that when firms compete à la Cournot in the second stage of the game, the complete network is pair-wise stable. When the difference between each country's tax rate on pollution emissions is beyond a certain threshold, the pair-wise stable graph is such that within each country all firms collaborate with one another, however there is no cross country R\&D collaboration. This has an important policy implication. Suppose a subgroup of countries agree to unilaterally adopt more stringent environmental policies such as larger taxes on pollution emissions than the countries that are not part of the agreement. The positive impact on the environment of such an agreement may be diminished (and outweighed) by the negative

\footnotetext{
${ }^{1}$ For empirical evidence see Landjouw and Mody (1996), Jaffe and Palmer (1997), Brunnermeier and Cohen (2003) and Jaffe et al. (2002) for an excellent survey.

${ }^{2}$ By equity-based $R \& D$ agreements, we refer to $R \& D$ joint ventures through which two or more firms agree to share assets (technology, capital, human resources) in the formation of a new entity under shared control aiming at innovation. Non-equity based R\&D agreements include contractual arrangements in which firms transfer technologies or commission $\mathrm{R} \& \mathrm{D}$ projects and informal relationships among firms.
} 
impact on international collaboration links to abate pollution emissions.

This paper belongs to the literature on network formation under strategic behavior in general (see, e.g., Goyal (1993), Jackson and Wolinsky (1996), Bala and Goyal (2000)) and more precisely to the recent literature on collaborative network formation (Kranton and Minehart (2001) and Goyal and Joshi (2003)). We follow closely the model of horizontal collaborative network formation of Goyal and Joshi (2003) to study a Cournot competition where (i) there are two subsets of firms each belonging to a given country that applies a specific tax rate on pollution emissions (ii) firms' production generates pollution emissions and (iii) firms can, prior to the competition phase, form collaborative links to reduce their emissions/output ratio. This paper also contributes to the literature on unilateral adoption of environmental and resource regulations (e.g. Hoel (1991), Golombek and Hoel (2004) and Benchekroun (2002)). Our contribution is to determine the impact of unilateral regulations on $\mathrm{R} \& \mathrm{D}$ collaboration to abate pollution emissions.

In Section 2 we briefly outline the model. Section 3 solves for the market equilibrium and investigates the externalities generated by link formation. Section 4 characterizes stable network architectures. Section 5 concludes the paper.

\section{The model}

We follow very closely the model of Goyal and Joshi (2003) and extend it to allow for two regions. Consider an industry composed of a set $N=\{1,2, \ldots, n\}$ of identical firms which compete à la Cournot-Nash in the same product market and produce a single homogeneous good. We assume that $n \geq 3$. Firms are located in two different countries, $A$ and $B$, and $N$ is partitioned in two subsets $N_{A}$ and $N_{B}$ of respective sizes $n_{A}$ and $n_{B}$. We suppose that firms have complete information about market structure and competitors' technology. The inverse demand function is given by $p=\alpha-Q$ where $\alpha>0, Q \equiv \sum_{i=1}^{n} q_{i}$ with $q_{i}$ denoting the quantity produced by firm $i$.

Without environmental regulation, firms use an identical technology characterized by a fixed emission/output ratio $s_{0}>0$. When governments introduce emission taxes, firms have an incentive to reduce their emission/output ratio prior to competing in the market. For simplicity, we assume that individual producers have no technology available for abating pollution. However, firms can make a more effective use of their technology and reduce their pollution emissions through collaborative $\mathrm{R} \& \mathrm{D}$ and information exchange. There are two stages. In the first stage firms have an opportunity to form pair-wise collaborative links with other firms and acquire a cleaner technology (i.e., an emission/output ratio smaller than $s_{0}$ ). In the second stage all firms compete à la Cournot in the market of output.

We describe the bilateral relationships that may occur in the first stage in graph- 
theoretic terms. The binary variable $g_{i, j} \in\{0,1\}$ indicates whether the pair of firms $(i, j) \in N$ conducts joint $\mathrm{R} \& \mathrm{D}$ activities. The value of $g_{i, j}$ is 1 when firm $i$ and firm $j$ establish a collaborative link (i.e., conduct joint $R \& D$ activities) and 0 when they don't. A network $g=\left\{\left(g_{i, j}\right)_{i, j \in N}\right\}$ provides an inventory of all bilateral ties that have been established within the industry. We let $\mathcal{G}$ denote the set of all networks. Furthermore, we let $g+g_{i, j}$ (respectively, $g-g_{i, j}$ ) denote the network obtained from $g$ by addition (deletion) of the link between the pair $(i, j)$. Let $\eta_{i}(g)$ denote the number of links established by firm $i$. A network $g \in N$ is said to be symmetric if every firm has the same number of links. Examples of symmetric networks include the empty network, $g^{e}$, in which $\eta_{i}\left(g^{e}\right)=0, \forall i \in N$ and the complete network, $g^{c}$, in which $\eta_{i}\left(g^{c}\right)=n-1, \forall i \in N$. We denote by $g^{A+B}$ the network where any two firms that belong to the same country are linked but no cross countries' link is formed:

$$
g^{A+B}=\left\{g_{i, j}=0, \forall(i, j) \text { such that } i \in N_{A}, j \in N_{B} \text { and } g_{i, j}=1 \text {, otherwise }\right\} .
$$

We are now in a position to describe how interfirm cooperation affects the emission technology of the firms. For an arbitrary network $g \in \mathcal{G}$, firm $i$ 's emission/output ratio is given by $\varepsilon_{i}(g)$. In the remainder of this paper, we assume that a firm's emission/output ratio depends exclusively on the number of bilateral links it has with other firms; i.e., $\varepsilon_{i}(g) \equiv \varepsilon_{i}\left(\eta_{i}(g)\right)$. More precisely, we assume that $\varepsilon_{i}($.$) is$ strictly decreasing in $\eta_{i}(g)$. Hence, we have $\varepsilon_{i}\left(\eta_{i}\left(g^{e}\right)\right)=\varepsilon_{i}(0)=s_{0}$ and $\varepsilon_{i}\left(\eta_{i}(g)\right)>$ $\varepsilon_{i}\left(\eta_{i}(g)+1\right) \geq 0$, for all $i \in N$ and all network $g \in \mathcal{G}$.

Since fewer emissions means reduced tax payments, each network $g \in \mathcal{G}$ generates a different cost configuration for the industry. Let $\tau_{i}$ denote the tax per unit of pollution emissions that firm $i$ pays. When producing a unit of output, firm $i$ is assumed to incur a constant marginal cost $c \geq 0$ and the tax that it pays on the pollution emitted to produce that unit of output $\tau_{i} \varepsilon_{i}\left(\eta_{i}(g)\right)$. Hence, firm $i$ 's effective marginal cost is $c_{i}^{e}(g) \equiv\left(c+\tau_{i} \varepsilon_{i}\left(\eta_{i}(g)\right)\right)$ and the cost configuration of the industry is defined as $c^{e}(g) \equiv\left\{c_{i}^{e}(g)\right\}_{i \in N}$.

Definition 1 (Pair-wise stability) Let $\pi_{i}(g)$ denote firm i's (equilibrium) profit at the second stage. We say that a network $g \in \mathcal{G}$ is pair-wise stable if the following conditions are satisfied:

Condition 1 for $g_{i, j}=1, \pi_{i}(g)>\pi_{i}\left(g-g_{i, j}\right)$ and $\pi_{j}(g)>\pi_{j}\left(g-g_{i, j}\right)$,

Condition 2 for $g_{i, j}=0$, if $\pi_{i}\left(g+g_{i, j}\right)>\pi_{i}(g)$, then $\pi_{j}\left(g+g_{i, j}\right) \leq \pi_{j}(g)$.

In other words, a network structure $g \in \mathcal{G}$ is said to be stable if every pair of linked firms has a strict incentive to maintain its link and no pair of unlinked firms has a strict incentive to set a new link. This definition, borrowed from Goyal and Joshi (2003), adapts the definition of pair-wise stability in Jackson and Wolinsky (1996) to capture the idea that the cost of forming a link is small but positive. 


\section{Market equilibrium}

Given an arbitrary network $g \in \mathcal{G}$, firms (in stage two) compete à la Cournot in the market of output. It can be shown that the equilibrium quantity produced by firm $i$ is given $b^{3}$

$$
q_{i}^{N}(g)=\frac{1}{(n+1)}\left[(\alpha-c)+\sum_{j \neq i} \tau_{j} \varepsilon_{j}\left(\eta_{j}(g)\right)-n \tau_{i} \varepsilon_{i}\left(\eta_{i}(g)\right)\right], \quad \forall i \in N
$$

and its equilibrium profits as $\pi_{i}\left(q_{i}^{N}(g)\right)=\left(q_{i}^{N}(g)\right)^{2}, \forall i \in N$.

Each firm's equilibrium profit is increasing in the number of its links and decreasing in the number of links of its competitors.

The formation of a link generates externalities. When two firms agree to collaborate, they both enjoy a symmetric reduction in their emission/output ratio. Each signatory firm thus enjoys a lower effective marginal cost than non-signatory firms. The marginal effect of the formation of a link between a pair of firms $(r, k) \in N$ on firm $i$ 's equilibrium quantity $(i \neq r, k)$ is given by

$$
\Delta q_{i}\left(g+g_{r, k}\right)=\frac{1}{(n+1)}\left[\tau_{k} \Delta \varepsilon_{k}\left(\eta_{k}\left(g+g_{r, k}\right)\right)+\tau_{r} \Delta \varepsilon_{r}\left(\eta_{r}\left(g+g_{r, k}\right)\right)\right]<0 .
$$

Since

$$
\Delta \pi_{i}\left(g+g_{r, k}\right)=\left(q_{i}(g)+q_{i}\left(g+g_{r, k}\right)\right) \Delta q_{i}\left(g+g_{r, k}\right)<0
$$

such a link between firms $r$ and $k$ affects negatively any other firm $i$ in the industry.

The effect of a link between firms $i$ and $k$ on firm $i$ 's equilibrium quantity is equal to

$$
\Delta q_{i}\left(g+g_{i, k}\right)=\frac{1}{(n+1)}\left[\tau_{k} \Delta \varepsilon_{k}\left(\eta_{k}\left(g+g_{i, k}\right)\right)-n \tau_{i} \Delta \varepsilon_{i}\left(\eta_{i}\left(g+g_{i, k}\right)\right)\right]
$$

Remark 1: The stability conditions of a graph $g$ can be stated in terms of changes in the equilibrium quantities produced by each firm. A link between firms $i$ and $k$ is formed iff $\Delta q_{i}\left(g+g_{i, k}\right)>0$ and $\Delta q_{k}\left(g+g_{i, k}\right)>0$.

\footnotetext{
${ }^{3}$ Given $\alpha, c$ and $\left(\varepsilon_{k}\right)_{k \in N}$ we limit our attention to the set of pollution emissions taxes that yields an interior equilibrium: $q_{i}^{N}(g) \geq 0$ for all $i \in N$ and all $g \in G$. We limit our attention to the set of parameters $\left(\alpha, c, n_{A}, n_{B},\left(\tau_{k}\right)_{k \in N}\right.$ and $\left.\left(\varepsilon_{k}(.)\right)_{k \in N}\right)$ such that $q_{i}^{N}(g) \geq 0$ for all $i \in N$. Such a set is clearly non empty, indeed for any $n_{A}, n_{B},\left(\tau_{k}\right)_{k \in N}$ and $\left(\varepsilon_{k}(.)\right)_{k \in N}$ we have $q_{i}^{N}(g) \geq 0$ for all $i \in N$ and all $g \in G$ provided $\alpha-c$ is large enough.
} 


\section{Stable networks}

We start by considering a specific functional form of firms' emission/output ratio and then discuss the generalization of our qualitative results.

The specific emission/output ratio function we use is an affine decreasing function of the number of agreements signed

$$
\varepsilon_{i}\left(\eta_{i}(g)\right)=s_{0}-s_{1} \eta_{i}(g), \quad \forall i \in N,
$$

with $s_{0}, s_{1}>0$ and such that $s_{0}-s_{1}(n-1) \geq 0$. Note that $\varepsilon_{i}\left(\eta_{i}\left(g^{e}\right)\right)=\varepsilon_{i}(0)=s_{0}$. From (4), it can be verified that the marginal effect of an additional agreement between firm $i$ and firm $k$ on firm $i$ 's equilibrium quantity is given by

$$
\Delta q_{i}\left(g+g_{i, k}\right)=\frac{s_{1}}{(n+1)}\left(n \tau_{i}-\tau_{k}\right) .
$$

and, by symmetry, we have $\Delta q_{i}\left(g-g_{i, k}\right)=-\Delta q_{i}\left(g+g_{i, k}\right)$.

We assume that $\tau_{i}=\tau_{A}$ for all $i \in N_{A}$ and $\tau_{j}=\tau_{B}$ for all $i \in N_{B}$. In the case where $\tau_{A}=\tau_{B}$ it is straightforward to deduce from proposition 3.1 in Goyal and Joshi (2003) that the unique stable network is the complete network $g^{c}$. The question now is whether the stability of the complete network is robust to tax induced cost differentials.

The complete graph is unstable if condition 2 does not hold; i.e., there is a pair of linked firms $(i, j)$ that has an incentive to break its collaboration link. First, consider any pair of firms $(i, k)$ located in the same country. Observe that $\Delta \pi_{i}\left(g-g_{i, k}\right)=$ $\Delta \pi_{k}\left(g-g_{i, k}\right)<0, \forall(i, k) \in N_{A}$ and $\Delta \pi_{j}\left(g-g_{j, k}\right)=\Delta \pi_{k}\left(g-g_{j, k}\right)<0, \forall(j, k) \in N_{B}$. Hence, within each country all firms are better off retaining their collaboration links with one another.

Second, consider any pair of firms $(i, j)$ such that firm $i$ is in country $A$ and firm $j$ is in country $B$. From (4), both firms have an incentive to stay linked if and only if

$$
\Delta q_{i}\left(g-g_{i, j}\right)=-\frac{s_{1}}{(n+1)}\left(n \tau_{A}-\tau_{B}\right)<0
$$

and

$$
\Delta q_{j}\left(g-g_{i, j}\right)=-\frac{s_{1}}{(n+1)}\left(n \tau_{B}-\tau_{A}\right)<0
$$

This condition gives

$$
n \tau_{A}-\tau_{B}>0 \text { and } n \tau_{B}-\tau_{A}>0
$$

that is

$$
\frac{1}{n}<\frac{\tau_{A}}{\tau_{B}}<n
$$


We conclude that the complete network is stable as long as the tax differential between the two countries remains relatively small. However, if $\tau_{B} / \tau_{A} \geq n$ no firm $i \in N_{A}$ has an incentive to stay linked with a competitor $j \in N_{B}$. In other words, no perennial international collaboration will occur: the network $g^{c}$ is unstable.

Finally, observe that the instability of international R\&D agreements has no disruptive effect on those signed within each country. Hence, for large differences in tax treatments across the two countries, the segmented network $g^{A+B}$ is a stable network. Also, it can be checked that for any other network $g^{\prime} \neq g^{A+B}$ firms have an incentive to deviate either by forming a new local link or deleting an existing international link. Therefore, $g^{A+B}$ is the unique stable network.

The following proposition summarizes our findings.

Proposition 2 Let $\tau_{i}=\tau_{A}$ for all $i \in N_{A}$ and $\tau_{j}=\tau_{B}$ for all $j \in N_{B}$ then:

(i) for $\left(\tau_{A}, \tau_{B}\right)$ such that $\frac{1}{n}<\frac{\tau_{A}}{\tau_{B}}<n$, the unique pair-wise stable network is the complete graph $g^{C}$

(ii) for $\left(\tau_{A}, \tau_{B}\right)$ such that $\frac{\tau_{A}}{\tau_{B}} \leq \frac{1}{n}$ or $\frac{\tau_{A}}{\tau_{B}} \geq n$, the unique pair-wise stable network is the segmented graph $g^{A+B}$.

Proposition 2 states that the complete network is stable when the tax treatment of firms is not too different. This qualitative result is robust to the specification of the emission/output ratio.

We start by noting that the condition on the pair of tariffs $\left(\tau_{A}, \tau_{B}\right)$ in Proposition 2 (i) can be interpreted as a condition on the relative cost savings per unit produced that each firm achieves through an agreement with another firm. Indeed, from Remark 1, a link between firms $i$ and $k$ is formed iff $\Delta q_{i}\left(g+g_{i, k}\right)>0$ and $\Delta q_{k}\left(g+g_{i, k}\right)>0$. We also note ${ }^{4}$ that the terms $-\tau_{k} \Delta \varepsilon_{k}\left(\eta_{k}\left(g+g_{i, k}\right)\right)$ and $-\tau_{i} \Delta \varepsilon_{i}\left(\eta_{i}\left(g+g_{i, k}\right)\right)$ in the right hand side of (4) represent respectively the cost savings, per unit produced, for firm $k$ and firm $i$ from signing an agreement. Thus firms $i$ and $k$ will sign an agreement iff

$$
\frac{1}{n}<\frac{\tau_{i} \Delta \varepsilon_{i}\left(\eta_{i}\left(g+g_{i, k}\right)\right)}{\tau_{k} \Delta \varepsilon_{k}\left(\eta_{k}\left(g+g_{i, k}\right)\right)}<n
$$

that is when the two firms' cost savings are not too different. In the case where $i \in N_{A}$ and firm $k \in N_{B}$ this condition becomes

$$
\frac{1}{n}<\frac{\tau_{A} \Delta \varepsilon_{i}\left(\eta_{i}\left(g+g_{i, k}\right)\right)}{\tau_{B} \Delta \varepsilon_{k}\left(\eta_{k}\left(g+g_{i, k}\right)\right)}<n .
$$

\footnotetext{
${ }^{4}$ We thank an anonymous referee for pointing out this interpretation.
} 


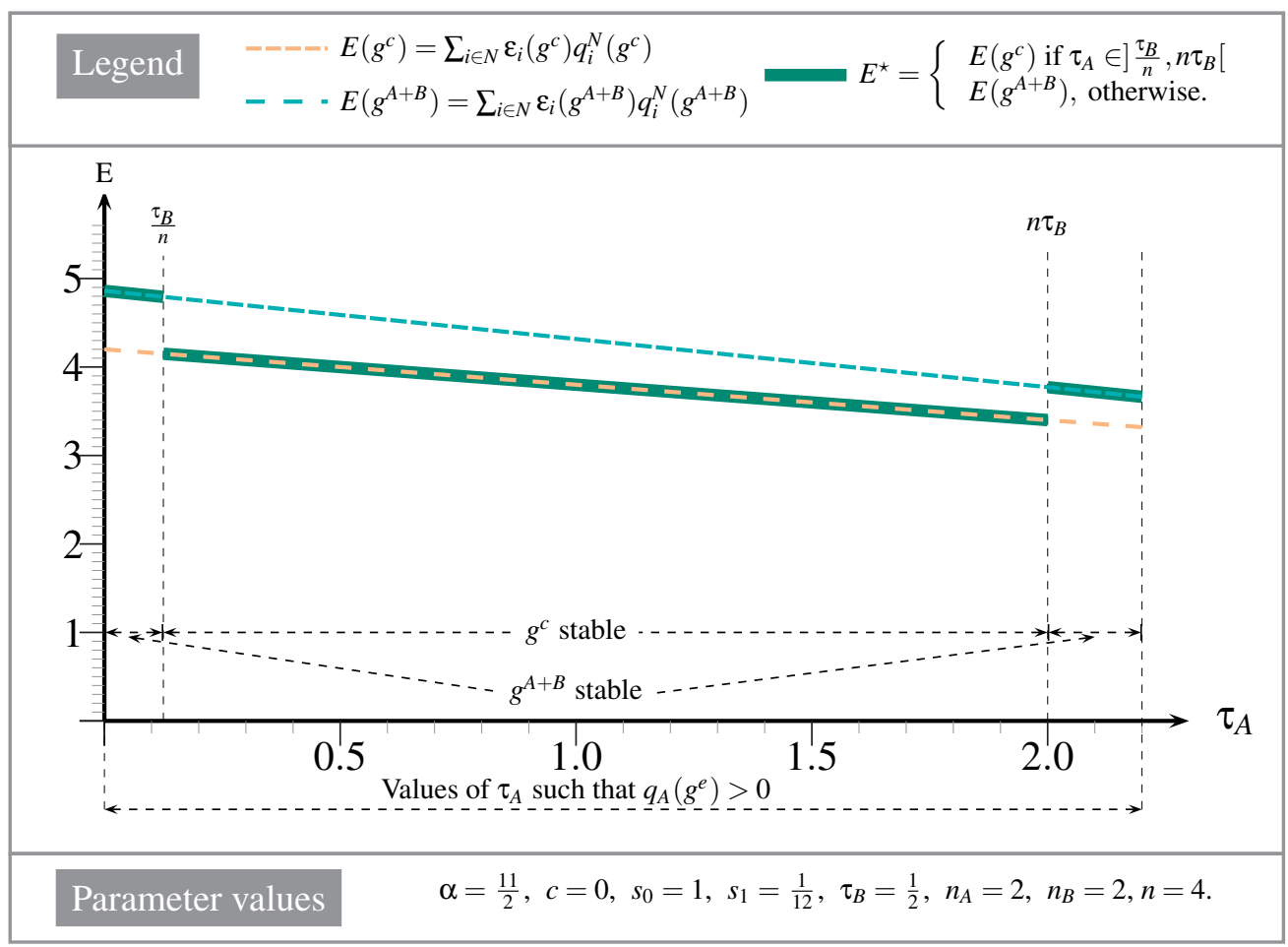

Figure 1: Total equilibrium emission levels.

Clearly, for any given emission/output ratio functions $\varepsilon_{i}($.$) , this condition is not$ satisfied when $\tau_{A}$ and $\tau_{B}$ are significantly different. Thus our qualitative results can be generalized to the case of other functional forms of firms' emission/output ratio, in particular to the case of strictly convex decreasing functions of the number of links.

Proposition 2 has an interesting implication. It can be shown that, given a tax rate $\tau_{B}>0$, the equilibrium total pollution emissions (i.e., from firms in both countries) may not be a decreasing function of $\tau_{A}$; it can jump upward at $\tau_{A}=n \tau_{B}$ :

$$
\sum_{k \in N} \varepsilon_{k}\left(\eta_{k}\left(g^{c}\right)\right) q_{k}^{N}\left(g^{c}\right)-\sum_{k \in N} \varepsilon_{k}\left(\eta_{k}\left(g^{A+B}\right)\right) q_{k}^{N}\left(g^{A+B}\right)<0 \text { when } \tau_{A}=n \tau_{B} .
$$

When $\tau_{A}$ is increased from $n \tau_{B}^{-}$to $n \tau_{B}$ firms break the cross countries collaborative links, which increases their emissions/output ratio. Consider the case where pollution is transboundary and suppose for example that both countries have a lax environmental regulation and are using an identical tax on pollution emissions $\tau_{l}$ that is positive but $\operatorname{small}^{5}$ (e.g., close to zero) and that Country A wishes to re-

\footnotetext{
${ }^{5}$ More precisely, $\tau_{l} \in\left\{\tau_{l}: q_{i}\left(g^{A+B}\right) \geq 0\right.$ for all $i \in N_{A}$ when $\tau_{B}=\tau_{l}$ and $\left.\tau_{A}=n \tau_{l}\right\}$..
} 
duce the total level of pollution emissions (e.g., due to political pressure from pro-environment lobby groups). If Country $\mathrm{B}$ refuses to change its tax on pollution emissions then Country A can consider unilaterally raising its tax on pollution emissions. However, such a unilateral increase of $\tau_{A}$ may have the exact opposite effect than the one intended: it may result in an increase in the level of pollution emissions (if $\tau_{A}$ is set beyond $n \tau_{l}$ ). This is illustrated in Figure 1 for the case where $n_{A}=n_{B}=2$.

\section{Concluding remarks}

We have built a simple model of network formation to examine how differences in environmental tax rates between two countries affect the architecture of stable collaboration networks in abatement of pollution emissions. We show that when the difference across countries in the tax rate on pollution emissions is below a certain threshold, the complete network is pair-wise stable: international R\&D collaboration to abate pollution emissions occurs. When the difference across countries in the tax rate on pollution emissions is beyond that threshold there is no across country R\&D collaboration to abate pollution emissions. This has an important policy implication. Suppose a subgroup of countries agree to unilaterally adopt more stringent environmental policies (e.g., larger taxes on pollution emissions) than the countries that are not part of the agreement. The positive impact on the environment of such a unilateral policy may be diminished (and outweighed) by the negative impact of the reduction in the level of R\&D across countries collaboration to abate pollution emissions. Such a unilateral action can endup increasing the level of pollution emissions.

We note that we have not explicitly formulated the cost of forming a partnership, and how it is distributed amongst firms that cooperate at the R\&D stage. Following Goyal and Joshi (2003) we have used a reduced form of the net benefit from cooperation in terms of reduction of emissions and assumed that in a second stage firms compete in the market of output. A relevant and promising line of future research is to make the cost allocation of cooperation explicit and study the sensitivity of stable networks to a change in the allocation rule adopted and to the degree of competition between firms in the market of output ${ }^{6}$.

\footnotetext{
${ }^{6}$ We thank an anonymous referee for suggesting this extensions.
} 


\section{References}

Bala, V. and S. Goyal (2000) A non-cooperative model of network formation, Econometrica 68, 1181-1231.

Benchekroun, H. (2002) Unilateral production restrictions in a dynamic duopoly, Journal of Economic Theory 111, 214-239.

Brunnermeier, S. and M.A. Cohen (2003) Determinants of environmental innovation in US manufacturing industries, Journal of Environmental Economics and Management 45, 278-293.

Golombek, R. and M. Hoel (2004) Unilateral emission reductions and cross-country technology spillovers, Advances in Economic Analysis \& Policy 4 (2), Article 3.

Goyal, S. (1993) Sustainable communication networks, Timbergen Institute Discussion Paper, Rotterdam, TI93-250.

- and S. Joshi (2003) Networks of collaboration in oligopoly, Games and Economic Behavior 43, 57-85.

Hagedoorn, J. (1996) Trends and patterns in strategic technology partnering since the early seventies, Review of Industrial Organization 11, 601-616.

Hoel, M. (1991) Global environmental problems: The effects of unilateral actions taken by one country, Journal of Environmental Economics and Management 20, 55-70.

Jackson, M. and A. Wolinsky (1996) A strategic model of social and economic networks, Journal of Economic Theory 71, 44-74.

Jaffe, A.B. and K. Palmer (1997) Environmental regulation and innovation: a panel data study, Review of Economics and Statistics 79, 610-619.

— ical change, Environmental and Resource Economics 22, 41-69.

Kranton, R. and D. Minehart (2001) A theory of buyer-seller networks, American Economic Review 91, 484-508.

Landjouw, J.O. and A. Mody (1996) Innovation and the international diffusion of environmentally responsive technology, Research Policy 25, 549-571. 